\title{
Percepção de gerentes sobre o papel gerencial em unidades básicas de saúde após capacitação na região sul da cidade de São Paulo
}

\section{Manager's perception on managerial role in Basic Health Units after capacity building course in Southern São Paulo City}

\author{
Fátima Madalena de Campos Lico \\ Secretaria Municipal de Saúde de São Paulo. Mestre em Psicolo- \\ gia. doutoranda do Programa de Pós-graduação em Saúde Pú- \\ blica da Faculdade de Saúde Pública da USP e monitora do Pro- \\ jeto GERUS São Paulo. \\ E-mail: fatimalicoœuol.com.br

\section{Maricene Ceravolo de Melo Ferreira} \\ Secretaria Municipal de Saúde de São Paulo, Cirurgiã Dentista e \\ monitora do Projeto GERUS São Paulo.

\section{Cleide Lavieri Martins} \\ Prof ${ }^{a}$ Doutora do Departamento de Prática de Saúde Pública da \\ Faculdade de Saúde Pública da USP, membro do Grupo de Co- \\ ordenação do Projeto GERUS São Paulo. \\ E-mail: cleideœusp.br

\section{Rosilda Mendes} \\ Doutora em Saúde Pública e pesquisadora do CEPEDOC Cidades \\ Saudáveis. \\ E-mail: rosildaœusp.br
}

\section{Resumo}

No processo de consolidação do SUS, na cidade de São Paulo, a descentralização compreendeu a criação de 39 Distritos de Saúde e a capacitação em gerência de unidades básicas de saúde surgiu como uma das propostas de reorganização dos serviços. O I Curso de Especialização em Gerência de Unidades Básicas de Saúde do SUS / SMS-SP - GERUS - foi desenvolvido, em 2002, na região sul da cidade, pela Secretaria Municipal da Saúde e pela Faculdade de Saúde Pública/ USP. Os objetivos deste estudo foram conhecer as percepções dos gerentes sobre o papel da gerência das unidades básicas de saúde, numa região de mananciais, populosa, com problemas de infra-estrutura e de exclusão social e analisar as contribuições do GERUS no desenvolvimento de capacidades dos gerentes. Foi empregada abordagem qualitativa, a coleta de dados foi feita por meio de grupo focal, análise dos relatórios produzidos e auto-avaliações. Foram definidos três eixos de análise: ser gerente no contexto da descentralização; o papel da gerência em unidades básicas de saúde; e as contribuições do GERUS para o fortalecimento do papel gerencial. Pôde-se observar que o GERUS possibilitou a ampliação da visão do papel gerencial e o desenvolvimento das competências técnicas para a reorganização dos serviços, trazendo ganhos pessoais e para a instituição. Há, contudo, problemas que uma capacitação soluções em seu âmbito na medida que estes problemas a trascendem um processo pedagógico dessa natureza exige que, concomitantemente à capacitação, haja um compromisso político com as mudanças.

Palavras-chave: Gerência de serviços de saúde; Descentralização; Capacitação gerencial em saúde 
Abstract

In the process of consolidation of the Single Health System (SUS) in the city of São Paulo, the decentralization comprised, among other measures, the creation of 39 Health Districts and the qualification on management of basic health units. Such course emerged as one of the proposals for the organization of services. The I SUS - UBS Management Specialization Course -SMS-SP (GERUS) was carried out in 2002 in the southern area of the city by the Health Municipal Authority and the School of Public Health/ USP. The objective of the study was to collect the perceptions of managers on the role of management of the basic health units within a densely populated water source area presenting infrastructure problems and social exclusion. Qualitative approach was used and the data gathering was carried out by means of focal group and analysis of the resulting reports and the self-evaluations. Three categories were defined for analysis: being a manager in the decentralization context, the role of management in the basic health units and the contribution of GERUS for the strengthening of the managerial role. It was observed that GERUS was a qualification process that enabled the broadening of managerial role and the developing of technical competency for the re-organization of services. The qualification proved positive both at personal and institutional levels. There are, however, other problems that qualification alone is neither aimed at nor capable of solving. A pedagogical process of such nature demands that concomitantly to the qualification there is political commitment towards change. Keywords : Health Service Management; Decentralization; Health Managerial Qualification

\section{Introdução}

O processo de descentralização, em curso no país desde os anos de 1980, tem ocasionado profundas mudanças de diferentes ordens e possibilitado que os governos locais assumam novo papel de atores que estimulem práticas participativas e fortaleçam arranjos institucionais, que permitam conciliar múltiplos interesses em jogo para enfrentar os desafios e atender às necessidades e anseios da sociedade local.

Nesse sentido, torna-se fundamental buscar outras formas de intervenção que permitam a articulação de conhecimentos e experiências para a solução dos problemas sociais. Esse novo modelo implica em riscos e exige negociações que apontem para uma possibilidade efetiva de se realizar uma transformação no cenário da administração pública, tendo como objetivo o alcance de resultados positivos para a qualidade de vida da população (Inojosa, 1998).

Pode-se considerar que a radicalidade da descentralização no Brasil foi instituída a partir da implementação do Sistema Único de Saúde (SUS), resultado da luta histórica do movimento da Reforma Sanitária Brasileira que desde os anos 1940 vem empreendendo esforços para produzir uma mudança política e cultural na sociedade brasileira, tendo a saúde como eixo de transformação. Esse movimento pode ser considerado um dos movimentos sociais mais articulados em defesa da democratização da sociedade brasileira e da saúde e, por isso, ocupa no contexto sociopolítico um lugar fundamental, agindo como ator político e social e contribuindo com mudanças paradigmáticas, legislativas e administrativas (Westphal, Mendes e Comaru, 2004).

Há uma grande variação no processo de descentralização entre as diversas políticas sociais do Brasil, de acordo com os distintos contextos institucionais, com as estratégias de indução desenhadas, com os graus de coincidência de ações dos diferentes níveis e outros (Arretche, 1999). Em São Paulo, a implementação do SUS, aliada ao cenário da descentralização político-administrativa, com a criação de 31 subprefeituras, nos remete a esses e a outros desafios, como os de criar novas institucionalidades mais inclusivas e capacidades locais que contribuam para o desenvolvimento de uma cultura político-democrática. $O$ sucesso dessas iniciativas requer investimen- 
tos permanentes na precisão de papéis a serem desempenhados pelos diversos atores, uma vez que estes são os protagonistas das mudanças e da consolidação desses processos na cidade (Fernandez e Mendes, 2003).

Na área da saúde, estudos têm analisado a capacidade gerencial, as quais não atende às necessidades colocadas pelas novas concepções que levam em conta a produção social e a promoção da saúde (Santana, 1997, Vecina Neto e Terra, 1998, Mendes 1996). No SUS, isso significa investir em uma gestão autônoma, capaz de interagir com grupos das comunidades e entidades governamentais e não-governamentais, estabelecendo parcerias e desenvolvendo ações intersetoriais para a formulação de políticas públicas locais participativas, visando às condições de vida e de saúde da população. Portanto, uma nova forma de gestão das unidades de saúde, a partir da análise das atuais práticas gerenciais, com ênfase na negociação, na condução do processo de trabalho e no controle do processo produtivo assegurando a operação dessas unidades para a melhoria contínua da qualidade da prestação dos serviços, deve ser a o caminho para os cursos de formação gerenciais.

Na implementação de mudanças é necessário se levar em conta o fato de a situação de saúde ser resultado das condições gerais de vida da população. Portanto, torna-se imprescindível implementar diretrizes de capacitação que promovam não somente correções técnicas e administrativas, mas, sobretudo, mudanças no modelo assistencial, que visem à alteração das condições de saúde (Ferreira, 2004).

Abaixo uma breve descrição da descentralização da saúde na cidade de São Paulo permite demonstrar a potencial complexidade do processo de capacitação gerencial, nessa perspectiva.

Durante o período de 1993 a 2000 , a cidade de São Paulo vivenciou uma fase em que a política municipal de saúde caminhou "na contramão" do Sistema Único de Saúde - SUS. Nesse período, foi criado o Plano de Assistência à Saúde - PAS -, alicerçado em cooperativas médicas conveniadas com a Secretaria Municipal da Saúde - SMS, o que fez com que o município deixasse de receber o repasse de grande parte dos recursos destinados à saúde, proveniente do SUS. Nessa fase, os serviços municipais de saúde não foram gerenciados ou sequer direcionados para atender às exigências constitucionais, mantendo-se à distância dos pressu- postos e princípios que regem um sistema único integrado e público de saúde (São Paulo, 2001).

A gestão da cidade, iniciada em janeiro de 2001, buscava assegurar ao cidadão paulistano o direito à saúde, na perspectiva de consolidar o SUS na cidade. No Diário Oficial do Município de São Paulo - DOM, em 25/o1/2001 o Comunicado $n^{0} 1$, encontra-se a proposta de política de saúde para São Paulo. Destaca-se nesse documento a municipalização dos serviços, efetivada no ano de 2002, com a fusão das redes básicas de saúde estadual e municipal e a descentralização dos serviços de saúde. Criou-se, então, 39 Distritos de Saúde (DS), viabilizando uma gestão compatível com a dimensão territorial e populacional da cidade, e priorizou-se a implementação do Programa de Saúde da Família - PSF, como eixo estruturante da atenção básica. Ressalta-se, ainda, a importância da participação popular, por meio do Conselho Municipal de Saúde e de Conselhos Gestores, no controle e na fiscalização das políticas de saúde e dos recursos destinados ao SUS.

A gestão municipal avançou com a descentralização político-administrativa da cidade, em 2003, quando foram criadas 31 subprefeituras. Esse desenho organizacional potencializou a gestão local, já que cada uma das subprefeituras teve possibilidade de organizar e estruturar as ações a partir das necessidades do território. Os 39 Distritos de Saúde foram readequados à nova estrutura, transformando-se em 31 Coordenadorias de Saúde.

É importante se ter em mente que as variações nas formas de descentralização vão determinar a direção da política local. Não se pode definir ainda se essa iniciativa de descentralização no município de São Paulo se tornará de fato uma descentralização de transferência de poder do nível central para o local, ou, simplesmente, como referido por Hortale (1997), uma desconcentração, transferência de autoridade administrativa e não política, ou, ainda, uma delegação de responsabilidades gerenciais para organizações fora da estrutura central e controlada de forma indireta. A continuidade e a sustentabilidade desse processo na cidade poderá trazer mais elementos para essa análise.

Nesse novo desenho organizacional, visualiza-se uma mudança na intervenção da saúde e uma nova concepção da atenção básica no município, de base 
territorial, para a qual se fez necessário discutir e implementar a capacitação dos gerentes de unidades básicas de saúde, fundadasnas diretrizes do SUS. Reorganizar os serviços e instrumentalizar a gerência tornou-se uma necessidade. 0 grande desafio desse projeto era oferecer embasamento teórico para que os gerentes pudessem efetivamente desempenhar seu papel, dentro da sua realidade, realizando a integração ensino-trabalho. A proposta da Organização Pan-Americana de Saúde \% OPAS e do Ministério da Saúde \% MS, Projeto GERUS (gerência de unidades básicas de saúde) foi escolhida por ser um processo de desenvolvimento institucional e gerencial estratégico para o apoio à política de descentralização, implantação dos distritos de saúde e municipalização da atenção básica, num contexto de ação técnico-político de organização local, tendo como eixo estruturante o PSF.

O GERUS tem como atividade central o curso de especialização em gerência de unidades básicas de saúde, realizado em serviço, com carga horária de 460 horas. Em São Paulo, foi desenvolvido com a cooperação técnica da OPAS e do MS, por meio de uma parceria com a Faculdade de Saúde Pública da Universidade de São Paulo - FSP/USP. Os profissionais das equipes técnicas dos Distritos de Saúde desempenharam o papel de monitores, ou seja, facilitadores do processo ensino-aprendizagem. A capacitação técnico-pedagógica dos monitores foi realizada pelo MS e o acompanhamento e a supervisão do processo, pelos docentes da FSP. Por meio de grupos de trabalho, gerentes e monitores realizaram discussões, orientadas pelas sequêencias de atividades previstas no Guia de Desenvolvimento Gerencial das Unidades Básicas de Saúde do SUS (Santana, 1997).

O curso foi desenvolvido alternando-se momentos de concentração e dispersão. Nos momentos de concentração, foram realizados grupos de trabalhos, exposição dialogada com profissionais dos serviços de saúde da SMS, considerados especialistas no assunto abordado, plenárias com a participação de convidados, realizadas na região dos Distritos de Saúde e no CEFOR, e aulas ministradas na FSP, com o intuito de complementar as atividades desenvolvidas. Nos momentos de dispersão, foram realizadas tarefas nas Unidades Básicas de Saúde, na medida do possível, com o envolvimento da equipe da Unidade e com a supervisão dos monitores.
Esse processo exigiu a articulação de diversas esferas institucionais: da Secretaria Municipal da Saúde \% SMS, por meio do Centro de Formação dos Trabalhadores da Saúde (CEFOR), da Coordenação de Desenvolvimento da Gestão Descentralizada (COGest) e, na época, dos Distritos de Saúde. Para a capacitação dos gerentes do município foram desenvolvidos quatro cursos com 369 gerentes e 103 monitores. O I Curso de Especialização em Gerência de Unidades Básicas envolveu os DS da região sul da cidade, no período de 19/02/2002 a 12/12/2002. Antes da criação das subprefeituras, essa região era formada por oito DS, Santo Amaro, Cidade Ademar, Grajaú, Parelheiros, Campo Limpo, São Luís, Capão Redondo e Jardim Ângela. e foi escolhida para iniciar o Projeto em função de o processo de municipalização da saúde na cidade ter sido iniciado nessa região.

Diante da complexidade das necessidades sociais apresentadas na região e do contexto de mudanças na gestão municipal, era dúvida se o processo de capacitação possibilitaria aos gerentes um novo papel neste cenário, o de articuladores, mobilizadores, negociadores e catalizadores locais mediante as exigências geradas nos serviços de saúde em termos de uma nova gestão.

Diante desse quadro o presente trabalho tem como objetivo conhecer percepções dos gerentes sobre o papel da gerência de unidades básicas de saúde, após a realização do Curso - GERUS, nos Distritos de Saúde de Socorro, Grajaú e Parelheiros, hoje Coordenadorias de Saúde de Socorro e Parelheiros, assim como analisar a contribuição do GERUS no desenvolvimento de um novo papel gerencial.

\section{Caminho Metodológico}

Do ponto de vista metodológico, optou-se pela abordagem qualitativa, buscando, através da perspectiva histórico-social, aprofundar o objeto de conhecimento, ou seja, a percepção dos gerentes sobre a capacitação GERUS, por meio do entendimento das mediações e relações num contexto de mudanças de políticas públicas e de saúde, que fortaleceram os processos de descentralização. Buscou-se também captar os diferentes significados das experiências vividas, de forma a auxiliar a compreensão das relações estabelecidas entre os gerentes, suas ações e o contexto sociopolítico. 
A coleta de dados foi feita por meio de documentos produzidos por gerentes e monitores do GERUS \% avaliações e auto-avaliações \% e de grupo focal. A utilização de grupos focais na área de saúde no Brasil, especialmente em programas educativos, segundo Westphal e cols., 1996, possibilita que os participantes expressem percepções, crenças e representações sociais a respeito de um tema específico, permitindo às pessoas pensar coletivamente uma temática que faz parte do cotidiano.

Os dados coletados, nas diferentes fases deste trabalho, foram analisados através da triangulação metodológica. No contexto da pesquisa social, esse tipo de abordagem tem sido usuada quando múltiplos métodos de pesquisa são empregados para analisar um problema. A utilização de multimeios, própria da proposta de triangulação, garante uma maior validade de dados, ou seja, a operacionalização de vários métodos. Essa estratégia metodológica parte da constatação de que as ações sociais e falas dos atores devam ser contextualizadas a fim de esclarecer e aprofundar os aspectos da realidade. A validação dos dados não é realizada por meio de aferição de índices e dados, ou do somatório de dados qualitativos e quantitativos, tratase de uma analise das relações entre contexto e as ações (Patton, 1987, Adorno e Castro,1994).

\section{Cenário de estudo}

Os DS de Socorro, Grajaú e Parelheiros faziam parte da região conhecida como Capela do Socorro .Após o término do curso, em função da descentralização político-administrativa, foi dividida em duas subprefeituras: Capela do Socorro, com os Distritos Administrativos (DA) de Socorro, Cidade Dutra, Grajaú; e Parelheiros, com os DA de Parelheiros e Marsilac (Lei $\mathrm{N}^{\circ}$. 13.399/01/o8/2002).

Essas subprefeituras localizam-se em área de proteção de mananciais, e Parelheiros possui características predominantemente rurais. A população da Subprefeitura Parelheiros, de acordo com o Censo 2000, era de 111.240, crescimento populacional (1991- 2000) de 6,79, abrangendo a área de 361,o1 km² (Fundação IBGE). Destes, 14.793 residem em favelas, de acordo com dados da Secretaria de Habitação de São Paulo.

A população da Subprefeitura da Capela do Socorro era 563.922, apresentando um crescimento populacional de 3,72 (1991-200o), com uma densidade demográfica no ano 2000 de 4229, abrangendo uma área de 133,34 km². O DA do Grajaú apresenta uma das cinco maiores taxas de crescimento de São Paulo, 6,17 ${ }^{1}$. Além de ser o mais populoso (331.971 habitantes) é também o que apresenta o maior número de pessoas vivendo em favelas: 53.166 pessoas, ou seja, 19,5\% da população do distrito (IBGE, 1996). Na subprefeitura de Capela do Socorro, a população residente em favelas, no ano de 2000, correspondia a 132.177 ${ }^{2}$ habitantes.

O território de estudo \% Subprefeitura de Capela do Socorro e de Parelheiros \% possui 494,35 km², correspondendo a 1/3 da área da cidade de São Paulo, e 95\% dessa área é abrangida pela lei de proteção dos mananciais. A região inclui ainda as bacias do Guarapiranga, Billings e Capivari-Monos, que contribuem com cerca de $35 \%$ da água potável da capital paulista.

As subprefeituras de Capela do Socorro e de Parelheiros caracterizam-se por possuir uma população jovem e pauperizada. A população masculina de Parelheiros, na faixa etária de 10 a 24 anos, corresponde a 19.569 do total, e a feminina, a 19.727. Na Capela do Socorro, a população masculina, na faixa etária de 10 a 24 anos, corresponde a 91.263 , e a feminina, a 95.713 (IBGE, SEMPLA, 2002).Isso contribui para o estabelecimento das elevadas taxas de mortalidade por homicídio na região que em Parelheiros é de 102,40, e em Capela do Socorro 78,2033 e enquanto no município de São Paulo essa taxa é de 46,81 por 100 mil habitantes.

No DA de Grajaú, cerca de $20 \%$ da população tem entre 10 e 19 anos de idade. A população de 20 a 29 anos de idade também está próxima deste percentual, estando classificada no grupo 5 do Índice de Vulnera-

\footnotetext{
1 Fonte IBGE - Censos demográficos 1980/1991, contagem 1996 e Sinopse Preliminar do Censo 2000 - Secretaria Municipal do Planejamento - SEMPLA/DEINFO.

2 Fonte base cartográfica digital das favelas do município de São Paulo, Secretaria da Habitação, 20oo. Elaboração: Secretaria do Governo Municipal, Assessoria de Planejamento - Sisem (São Paulo, 2004 ${ }^{\text {aa }}$.

3 Fonte: Secretaria Municipal da Saúde, 2002. Obs.: População residente no município de São Paulo, 2002 - projeção com base no Censo demográfico 2000 do IBGE, considerando taxa de crescimento de 1991-2000.
} 
bilidade Juvenil ${ }^{4}$. Uma grande concentração de chefes de família recebe menos de três salários mínimos; em Grajaú, Parelheiros e Marsilac esse número corresponde a mais de $50 \%$ do total.

Considerando dados da Secretaria Municipal da Saúde, a subprefeitura Parelheiros apresenta um dos maiores Coeficientes de Mortalidade Infantil do município, 20,13 por mil nascidos vivos, sendo o coeficiente para o município 15,085 . Esse cenário revela um acentuado grau de exclusão social, com escassos recursos sociais e insuficientes equipamentos de saúde, além de problemas de infra-estrura.

São 27 os equipamentos de saúde da rede municipal nas subprefeituras: 19 na subprefeitura da Capela do Socorro e 8 em Parelheiros (São Paulo, 2004a). Destes, 19 são Unidades Básicas de Saúde (UBS), 13 na Capela do Socorro e 6 em Parelheiros. Essas Unidades são distintas de acordo co sua estrutura: algumas são municipais e outras foram municipalizadas. Umas possuem equipes do Programa Saúde da Família e outras não. Entre as diferenças dessas Unidades, destaca-se que as municipalizadas não possuem tabela de lotação de pessoal própria, nem estrutura de cargos e salários, o que acaba criando graves problemas de gerenciamento e descontentamento por parte dos profissionais de saúde.

A região das subprefeituras possui ainda, dois Pronto-Socorros Municipais, o Dona Maria Antonieta F. de Barros e o Pronto Atendimento Balneário São José; o PA Parelheiros; o Hospital Geral do Grajaú, da Organização Santamarense de Educação e Cultura; dois Ambulatórios de Especialidades (AE); um Centro de Convivência e Cooperativa (CECCO); um Serviço Assistência Especializada DST/AIDS (SAE Dutra) e um Posto de Atenção Médica (PAM Dutra).

\section{Coleta de dados}

Procurando conhecer as percepções dos gerentes sobre o papel da gerência de unidade básica de saúde, foi realizado o grupo focal com os dezoito gerentes, na avaliação final do curso. Para facilitar a participa- ção e a interação dos gerentes, optou-se por realizar dois grupos focais com duração de duas horas cada um. Um realizado no período da manhã e o outro, no período da tarde, no dia o6 de dezembro de 2002. Inicialmente ,apresentou-se o objetivo do trabalho e solicitou-se o consentimento dos participantes para a gravação da discussão, ressaltou-se ainda que os participantes não seriam identificados, reforçando a importância da confidencialidade.

Para a condução do grupo foi utilizado um roteiro temático (anexo). Os temas do roteiro foram apresentadas pelo coordenador do grupo focal, que solicitou aos participantes que os discutissem. Dois observadores cuidaram da gravação e também anotaram as falas dos participantes.

Além do grupo focal, procedeu-se a análise dos documentos produzidos pelos gerentes e monitores durante o curso, como relatórios de avaliação das unidades do curso, auto-avaliações, trabalhos executados pelos alunos, anotações em diários de acompanhamento de curso pelos três monitores da turma, em reuniões de supervisão e avaliação do GERUS.

\section{Tratamento e análise dos dados}

A leitura dos documentos e a transcrição das gravações dos grupos focais foi realizada a partir da análise temática do material, identificando-se as expressões, as idéias centrais e os sentidos atribuídos pelos gerentes ao, aos três eixos de análise, previamente definidos:

1. Ser gerente no contexto da descentralização.

2. O papel da gerência em unidades básicas de saúde.

3. As contribuições do GERUS para o fortalecimento do papel gerencial.

Para a análise do discurso, utilizou-se a fala dos atores sociais considerando no qual se inscrevem (Minayo e cols., 1994).

Os repertórios interpretativos, ou seja, o conjunto de termos, descrições, lugares-comuns e figuras de linguagem, denominados por Spink e Medrado (1999)

\footnotetext{
4 Índice de Vulnerabilidade Juvenil - elaborado para os 96 DA, a partir de cinco variáveis (taxa anual de crescimento populacional entre 1991 e 2000 , porcentagem de jovens de 15 a 19 anos, no total da população dos DA, taxa de mortalidade por homicídio da população masculina de 15 a 19 anos, porcentagem de mães adolescentes de 15 a 17 anos, no total de nascidos vivos, valor do rendimento nominal médio do responsável pelo domicílio e porcentagem de jovens de 15 a 17 anos que não freqüentam a escola), sendo o Grupo 1 o de menor vulnerabilidade social e o Grupo 5 o de maior.

5 Coeficiente de Mortalidade Infantil: fonte Fundação SEADE, 2002.
} 
como spenches genres e que emergiam nas falas, foram sintetizadas em quatro figuras básicas: o malabarista, o treinador, o negociador e o maestro.

$\mathrm{Na}$ análise, foram realizadas articulações entre os trrês eixos previamente definidos e as figuras identificadas na leitura do material empírico.

\section{Resultados e Discussão}

\section{Ser gerente no contexto da descentralização: 0 malabarista}

Os gerentes afirmam haver grande dificuldade de desempenhar seu papel no contexto em que atuam. Essa dificuldade está relacionada com a localização, a dimensão geográfica, a escassez de recursos sociais e de equipamentos de saúde e a falta de infra-estrutura básica. Situada no extremo sul da cidade de São Paulo, trata-se de uma região periférica, considerada pelos gerentes "um local abandonado pelas políticas públicas". De fato, essa região é caracterizada por uma alta densidade demográfica, devido às invasões ocorridas nesses últimos anos.

O exemplo de Marsilac exemplifica essa situação. É considerada uma área rural, com uma população de aproximadamente 8 mil habitantes (IBGE, 2000), 200 mil km² e 23,74 de densidade demográfica, com dificuldades de acesso, contando apenas com uma unidade de saúde com três equipes de Saúde da Família, inaugurada em 2001, situada em uma estrada vicinal, onde para chegar a população percorre $5 \mathrm{~km}$; e, as agentes comunitárias de saúde até $15 \mathrm{~km}$, em áreas violentas, para visitar as famílias sob sua responsabilidade.

Além dessa dificuldade de acesso, observa-se que a relação população e unidade básica de saúde nas áreas de abrangência dos outros três Distritos Administrativos estudados é de uma unidade para cerca de 40 mil habitantes, e o Plano Metropolitano de Saúde - PMS, 1983 define como parâmetro 1 UBS para 20 mil habitantes. Soma-se a isso o déficit de médicos. Segundo estudos da Coordenadoria de Saúde de Socorro ${ }^{6}$, no Grajaú, para uma população de 351.789 habitantes com $58 \%$ SUS dependente seriam necessários, observando-se o parâmetro 1/20oo hab, 112 médicos; a região conta apenas com 67.

Diante desse quadro, aliado à falta de referências e contra-referências, à falta de infra-estrutura e a desmotivação dos funcionários, os gerentes se vêem constantemente administrando conflitos e sofrendo pressões de várias ordens - dos níveis regional e central da SMS, da mídia, da população e dos próprios funcionários - para oferecer um atendimento resolutivo e de qualidade:

“(...) eu vejo gerência como administração de conflitos, administração de RH que é o grande problema nosso administrar RH, é uma dificuldade, administração de materiais, administração de políticas de saúde, administrar tudo isso (...) falta isso e falta aquilo (...)"

“(...) dificuldade de ser gerente da região, é aquele medo mesmo de uma reportagem, de repente, de você como gerente virar artista da Globo (...) “

Muitos desses conflitos são decorrentes do próprio processo de descentralização, que teve características marcantes de desconcentração e delegação. 0 exemplo da escassez de recursos, físicos, materiais e humanos, apontada pelos gerentes, como as principais dificuldades, indica ainda a existência de forte centralização das políticas na SMS. A inadequação da transferência de recursos financeiros e da política de recursos humanos, que segundo os gerentes não consideram os reais problemas de saúde da população e conseqüentemente não contemplam as necessidades de uma região periférica, constituem grandes obstáculos para a tomada de decisão no nível local.

"Eu não acredito que o nível Central que tem que determinar quantos funcionários que eu tenho que ter, qual a categoria que eu tenho que ter, se eu só posso ter tantos ou tantos profissionais baseados no número de sala, no número de (...), sabe, que a gente tenha mais autonomia para propor. E que a gente possa ter oportunidade de compensar algumas coisas, por exemplo, se na unidade eu não tenha condição de lutar para ter um profissional médico então eu tenho disponibilidade de lutar com mais enfermeiros para que eu possa otimizar um pouco mais aquele recurso (...) que eu possa utilizar melhor aquele recurso que eu tenho, que eu possa atender melhor àquela demanda que eu tenho (...)"

6 Fonte: Consulta Pública, №. 1 de o8/12/200o, Censo 200o, projeção populacional 2003; Instituto Pólis, 1998, SIAB o9/2003, RH, dez./ 2003. 
“(...) para desempenhar o papel de gerente você tem que ter uma estrutura acima da sua, muito resistente (...) com critérios claros e te subsidiando a todo momento. Conhecendo a sua área de abrangência, a área de abrangência do município todo, sabendo, ouvindo a região para saber os recursos que precisa, dando respostas para estes recursos(...)Só nesse pedacinho da zona sul a gente tem região com características extremamente distintas, a gente pode colocar que a gente tem um Brasil inteiro onde você tem a região sul e o nordeste dentro só dessa região. (...) são características infinitamente distintas, contrárias e eu muitas vezes vejo que a nível central não observa isso."

Além disso, os gerentes referem-se a uma falta de sincronia entre os diferentes níveis de governo e os programas de saúde propostos.

"O gerente hoje ele é do ponto de vista hierárquico o menor de todos mas ele é o que mais tem servido hoje, hoje ele tem que sentar na mesa, discutir (...) tem que ter uma certa autonomia, ele não pode só receber pacote de todo lado, acho que o Município e o Estado, o Município e o Governo Federal precisam ter uma sincronia maior do ponto de vista de programa, tá certo? O Município tem a sua programação a ser cumprida e o Ministério da Saúde está bombardeando de todo lado (...) precisa existir mais sincronia na programação de tarefas para gente, (...) do ponto de vista administrativo e do ponto de vista de RH acho que está falência total (...)

Percebem, ainda, a descontinuidade das ações, presente nos serviços públicos, resultante da falta de planejamento e das mudanças políticas. Ser gerente tem sido um trabalho de construção e reconstrução, em função das mudanças que ocorreram no município: modelo de atenção à Saúde \% PAS, consolidação do SUS com o processo municipalização, distritalização, implantação do PSF e descentralização políticoadministrativa da cidade, com a criação das subprefeituras. Muitas vezes, essas mudanças geram descontinuidade e dificuldades de planejamento. Dessa forma, os gerentes se vêem diante de dificuldades estruturais e organizacionais, como, por exemplo: estrutura de cargos e salários diferenciada, falta de plano de carreira, de formação, de capacitação, e desmotivação dos funcionários.

"Quando muda o nível central e a pessoa que está a nível central tem uma visão diferente do processo de saúde você desestrutura todas as gerências que estão em baixo. Então eu acho que a importância é você ter uma base, uma base sólida, um processo sólido (...) Se você solidificar este processo ele vai ficar firme e ninguém consegue mudar muito a característica dele porque o fim é um só, é a saúde e o bem- estar da população, respeitando a característica de cada região.(...). e eu muitas vezes vejo que a nível central você não observa isso, a nível central em qualquer época, desde que eu estou na Prefeitura você se preocupa mais com a mídia no que a mídia vai falar. 0 embasamento da saúde, ele é meio corroído, é uma coisa, então você não tem uma solução de continuidade. 0 projeto de uma unidade básica de saúde, que eu acho que já está desde antes de eu nascer (...). ele é sempre mudado."

Apesar da falta de autonomia citada pelos gerentes, há uma expectativa muito grande de que esse quadro possa ser modificado com a descentralização. A partir da criação das subprefeituras, da capacitação técnica propiciada pelo GERUS, do conhecimento do seu território e dos problemas de saúde existentes na região, espera-se poder realmente planejar intersetorialmente as ações a serem desenvolvidas, e negociar com os atores envolvidos os diferentes recursos necessários para a operacionalização das ações propostas, objetivando assim uma melhor resolubilidade dos serviços.

Segundo os gerentes, a distritalização facilitou a interação das UBS entre si e com os respectivos Distritos de Saúde da época. Essa integração possibilitou a melhoria dos serviços prestados, diminuindo as deficiências das UBS, tornando o trabalho do gerente mais eficiente e eficaz. Destacam-se a importância do acolhimento, da união e da solidariedade existente entre os diretores dos distritos e entre os próprios gerentes, na busca da melhoria da qualidade de vida da população e das condições de trabalho nas UBS.

De acordo com os gerentes, a integração, a solidariedade e os vínculos já existentes, foram reforçados e acentuados no território, com desenvolvimento do curso GERUS. Isso foi possível devido à organização do curso, à metodologia adotada e o desenvolvimento do curso por monitores dos distritos de saúde.

"Eu acho que o curso também nos proporcionou uma proximidade maior entre os gerentes, que quando foi para gente inaugurar a unidade lá no Marsilac, se eu não tivesse começado o GERUS, eu acho que eu 
tinha saído da canoa, porque foi assim, uma inauguração meio de repente, tinha uma pressão muito forte da comunidade, mídia em cima, todo dia tinha a Rede Globo lá falando do Marsilac e às vezes não tinha recebido nem o material, nem equipamento, nada, tínhamos apenas o prédio, então com a ajuda dos amigos em menos de dois dias a gente estava com a unidade montada e que ela está lá até hoje daquele jeito que foi montada, tudo bem (...)"

Para os gerentes, o exercício do seu papel na região tem sido um "vôo livre e solitário", mas com a proposta da descentralização esta situação está mudando, abriram-se caminhos para a realização do trabalho intersetorial e para uma efetiva participação popular, com a constituição dos conselhos gestores. Por outro lado, o processo de descentralização político-administrativa da cidade traz medo e insegurança. Com a criação das subprefeituras, os gerentes receiam que os aspectos políticos e partidários predominem em detrimento dos aspectos técnicos, e que isso possa mais uma vez prejudicar os projetos de melhoria da qualidade de vida da população.

A preocupação de perder o cargo que ocupam também está presente. Por possuírem cargo de confiança da atual direção do Distrito de Saúde, os gerentes acreditam que possam haver substituições das gerências de UBS, porém esperam que ética e compromisso com a população predominem e que a "descentralização não fique apenas no discurso".

Diante do exposto, os gerentes consideram que desempenhar o papel gerencial, nesse contexto, é um grande desafio. Ser gerente nesse contexto:

"requer muita disposição, (...) tem que ir com vontade, com coragem, tem que ser malabarista (...) de vez em quando tem que dar um toque para o outro, para ajudar a segurar os malabaris. Os malabaris são os desafios, falta de RH (...) de recursos materiais (...) financeiros. É uma coisa que você precisa acreditar, que você pode fazer a diferença (...) ter clareza que você tem uma missão.”

\section{o papel do gerente na unidade básica de saúde: o treinador}

À imagem do gerente, como malabarista, como mencionado anteriormente, é acrescida outra, a do treinador de um time de futebol, que desenvolve um trabalho de identificação e preparo de lideranças poten- ciais. Seu papel de gerência é participar da "integração social na região, fazer articulações, ser presente e político".

O gerente deve lutar para que a situação de desmotivação e de desmantelamento, anteriormente vivenciada, não retorne. Deve saber lidar com as mudanças e desarticular movimentos destrutivos. Deve ressaltar a necessidade de mudar, de envolver as pessoas, de desenvolver ações e de ter pensamentos positivos.

"O treinador deve planejar, ter respaldo e recursos, fazer a equipe jogar, mudar e ganhar o jogo. 0 papel do gerente é motivar o funcionário. Dar subsídios para ele trabalhar. 0 seu papel adquire significado importante quando exerce uma administração participativa, valorizando funcionários, clientes, como sujeitos integrantes de um processo de transformação social."

“(...) tem que gostar e aprender a delegar, ter visão de integração e conhecimento da Unidade de Saúde e do seu território, ser generalista, administrar e ter o papel de integrar."

No decorrer do GERUS, os gerentes foram identificando o papel de negociador como essencial e necessário ao exercício da gerência. Exercer esse papel de negociador significa buscar o consenso e assumir riscos não somente em relação a sua inserção no sistema de saúde, mas também em função da equipe da unidade. Os depoimentos ressaltam duas dimensões do papel do gerente, uma objetiva, a da técnica de gerenciamento, e outra subjetiva, das emoções e das formas de entender e estabelecer as relações pessoais.

“(...) descobrimos que nós, gerentes, temos as características de um grande negociador, portanto a capacidade de negociação é um atributo indispensável para o desempenho gerencial.

"Ser gerente é ser maduro, ter qualidades pessoais, ser bom comunicador, estimular a equipe. 0 gerenciamento é uma técnica a ser conquistada. A gerência vai se aprimorando, crescendo e amadurecendo. É administração de conflitos, administrar RH, materiais, administrar faltas. É uma experiência pessoal, crescimento. É um processo que exige avaliação clínica, precisa ser rápido, inteligente, observador e ter muita capacidade de ouvir. Ouvir com o coração e com perspectivas de horizontes diferentes.

Negociar não é uma tarefa simples. No contexto onde se inserem, as dificuldades para aplicá-la são potencializadas, o que requer do gerente preparo pes- 
soal para o enfrentamento das situações cotidianas:

“(...) ser gerente requer uma manutenção pessoal, ficar zen, exercer atividade física, e ter uma convivência saudável no grupo, para poder estar com a parabólica pronta, saber de tudo, entender, controlar, refletir, buscar saídas rápidas, para a gente poder pegar a flecha e atirar no palco.

Apesar de tantas dificuldades enfrentadas após "tanto tempo de abandono, exclusão e maltrato dos serviços de saúde", os documentos analisados, especialmente o trabalho denominado "A voz do gerente", realizado pelos gerentes como conclusão final de curso, apontam que eles se sentem gratificados ao perceberem a possibilidade de realizar o exercício do planejamento e da negociação e indicam a implantação do PSF, que vem reorientando os serviços de atenção básica, como umas das estratégias de motivação.

\section{Contribuições do curso GERUS para o fortalecimento do papel gerencial: aprender a ser maestro}

De modo geral, pode-se notar que os depoimentos apontam que o GERUS possibilitou, por um lado, uma maior apropriação do território, do planejamento e da negociação como instrumentos de gerência e, por outro, a integração entre os gerentes da região.

De fato a dinâmica do curso obrigou um conhecimento detalhado do território. Os objetivos da Unidade $\mathrm{I}^{7}$ possibilitaram aos gerentes descrever a população da área de abrangência da unidade de saúde, suas características demográficas e condições de vida; analisar a estrutura de morbi-mortalidade; identificar e descrever tipos de serviços oferecidos à população e produção existentes na unidade; identificar e descrever os recursos sociais existentes na área, instituições e equipamentos cuja ação ou utilização têm reflexos sobre a saúde; analisar o grau de articulação desses recursos, a cobertura, o impacto e o grau de satisfação da população em relação aos serviços produzidos; identificar as forças sociais que determinam a organização e o funcionamento dos serviços de saúde, analisando a racionalidade subjacente à sua atual organização.

Os gerentes, por meio de mapeamentos e de visitas, puderam realizar sínteses que resultaram em cole- tâneas de informações sobre o território - "book da unidade". Isso, aumentou a capacidade de o gerente observar a realidade, a população, a história local, e contribuiu para o aperfeiçoamento e aprendizado técnico

“(...) colaborou demais e me ajudou a abrir os horizontes, a ver a população como um todo e não ver mais aquela parte fragmentada e tentar enxergar o meu território, a minha demanda a minha população e o meu pessoal (...)"

“(..) pensar essa coisa da programação da Unidade, de você entender qual é o problema, onde é que está, onde que a coisa está começando o que é que aquela questão vai acarretando, isso faz a gente crescer, não é, a gente tem uma visão maior das coisas. Agora eu só acho que a gente precisaria pensar um modelo de passar isso melhor para a Unidade (...)e também começar a envolver a população nessa discussão porque na medida em que você determina quais são as prioridades que você vai trabalhar no próximo ano, qual é a sua programação, a gente tem que (...) convencer não é, a população que isso é o melhor, eu vou atender a gestante por isso (...) que eu não vou atender essa e essa outra demanda porque o recurso é limitado, eu não tenho pessoal para atender toda a demanda que vai na minha porta, eu tenho os quarenta e poucos mil habitantes da minha área de abrangência, mas eu tenho cinqüenta mil habitantes da minha área de influência, então eu não vou dar conta(...)

A participação nesse processo trouxe para perto o planejamento e a negociação que poderiam permitir mudanças de relação e novas articulações com os diferentes níveis hierárquicos da Secretaria Municipal da Saúde, com os funcionários e com a população.

"eu acho que a gente vai conseguir ter um pouco mais de elementos para negociar, com a questão administrativa mesmo, então eu acho que isso a gente aprendeu no GERUS, porque hoje em dia a gente não pode falar não, eu não vou fazer uma campanha de papanicolau, agora se eu explicar o porque eu não vou, porque, onde eu acredito que a minha população já está sendo atendida nessa campanha, tudo isso, eu acho que a gente vai ter um pouco mais de força, porque hoje a idéia que se tem é que a unidade a gente

70 Curso de Especialização em Gerência de Unidades de Saúde possuía três unidades didática: Unidade I - Avaliação das condições de vida da população e da estrutura e funcionamento das unidades de saúde (18o h), Unidade II - Reorganização dos serviços de saúde (140 h), Unidade III - Operação da Unidade de Saúde (140 h). 
nunca planeja nada, porque a gente nunca teve o hábito de planejar (...) tudo foi feito em cima das iniciativas das pessoa (...)"

Para a maioria dos participantes foi um desafio pessoal e profissional, uma oportunidade de crescimento. A transformação foi perceptível, com "mudanças internas e pessoais".

"O GERUS para mim, (...) eu nunca mais vou ser a mesma depois do GERUS (risos) eu acho que ele colabora para gente quanto gerente, eu acho que todos os profissionais, eu acho que poderiam a gente passar por um processo parecido, não tão longo, mas parecido. Eu acho que o GERUS é uma coisa que eu procurava."

" o GERUS enriqueceu muito, acrescentando assim, com as próprias discussões entre a gente, a gente aprendeu muito, acho que até mais do que com leitura de textos, quando a gente discutia, rolava até altos quebra-paus, chegou lá mesmo de um olhar feio para o outro depois, mas eu acho que foi muito válido e isso acrescentou muito e o que a gente estava discutindo ontem que deu sim um embasamento teórico para gente ter, tomar decisões eu acho que ajudou bastante nisso né, em tomada de decisões porque a gente quando lia o texto de negociações a gente ia se comparando ah eu sou assim, eu sou assado, não, mas em certas situações eu tenho que ser assim, então acho que ajudou bastante e enriqueceu muito para esta integração e as discussões no grupo, acho que acrescentou muito assim, de conhecimento."

Durante o curso, ocorreram muitas mudanças político-administrativas na cidade e na SMS, e os gerentes consideraram o GERUS um processo positivo para essas mudanças, uma vez que ele possibilitou a integração com as unidades de saúde, o acolhimento pelo distrito, a criação de vínculos e a superação de conflitos.

“o GERUS nos deu vários subsídios suficiente para estar trabalhando a nossa região para nortear de um modo diferente de que muita gente tinha pouco na unidade e também essa integração entre os gerentes que esse encontro era as vezes esporádico e a gente não conseguia reunir todos ao mesmo tempo. No início houve mesmo uma espécie de competição em que um tentava sobressair do outro tentando mostrar alguma coisa diferente, mas o caminho não era esse ou quem fez mostrou para gente que o caminho não era esse e que nós tínhamos mais é que trocar experiên- cias e idéias para gente poder caminhar melhor (...)"

"o GERUS nessa parte de integração dos gerentes foi assim uma coisa fantástica, inclusive agora a gente está chegando no fim do curso é um dando a mão para o outro, ajudando no que pode, a gente tem assim essa liberdade de ligar e pedir ajuda porque a gente tem certeza de que o colega não deixa a gente na mão então isso aí assim é uma coisa emocionante, deixa eu parar por aqui senão (...)."

Esses depoimentos revelam que o curso efetivou uma parceria e o acolhimento entre os próprios gerentes, o que proporcionou maior segurança para o desempenho do papel gerencial.

"o gerente é parte de uma orquestra, cuja partitura é o SUS (...) 'ser gerente é levantar a bandeira do que se tem como verdade, ser forte, ter uma missão, ser maestro. A partitura é o SUS e foi dada com o GERUS (...) é o norte.”

\section{Considerações Finais}

No processo de descentralização, em curso no município de São Paulo, foram implementados alguns mecanismos, buscando o desenvolvimento de uma política local mais autônoma, com a criação de novas instâncias de decisão que contribuíssem para a democratização dos diferentes níveis de gestão. O GERUS foi um desses mecanismos, e tinha como objetivo, por meio de um processo de capacitação, possibilitar aos gerentes de unidades básicas de saúde a ampliação da visão do papel gerencial e o desenvolvimento das competências técnicas para a reorganização dos serviços e para a participação dos gerentes como co-responsáveis, juntamente com diferentes setores na formulação e implementação da política pública local. Desta forma, com o GERUS, os gerentes estariam capacitados para contribuir para o fortalecimento de uma gestão descentralizada e participativa, a ser implantada com a criação das subprefeituras, aplicando os conhecimentos técnicos adquiridos para diagnosticar problemas, identificar potencialidades, definir prioridades de ações e realizar parcerias visando à melhoria da qualidade de vida da população.

No entanto, muitas dessas expectativas não puderam ser ainda concretizadas em função de uma série de determinantes. Alguns deles, que se referem ao papel gerencial, foram evidenciados neste estudo. 
Observa-se que recai sobre o gerente a responsabilidade de organização da base de um sistema de saúde, que vem sofrendo permanentes e significativas mudanças. 0 gerente reconhece a importância desse papel a ele atribuído, de condutor de uma política, assumindo ser o treinador e o maestro. Por outro lado, é também o malabarista num vôo livre e solitário, o que reforça as dificuldades pessoais e contextuais vivenciadas por ele. Não se pode desconsiderar o encantamento e as possibilidades referidas. Algumas vezes, esse é um caminho trilhado individualmente, que traz uma forte característica presente na área de saúde, o messianismo.

Não resta dúvida de que o processo de capacitação desenvolvido nos moldes do GERUS, de acordo com a percepção dos gerentes, trouxe claramente a discussão sobre o papel do gerente de unidade básica de saúde. Trouxe também ganhos pessoais e para a instituição. Há, contudo, outras problemáticas que uma capacitação não é capaz por si só de solucionar, como as vastas iniqüidades presentes na região de Marsilac, Parelheiros e Capela do Socorro. E nem é esta sua função. Um processo pedagógico dessa natureza exige que, concomitantemente à capacitação técnico-política, haja um compromisso político com as mudanças. No contexto da descentralização da cidade de São Paulo, permanece o grande desafio de gerar processos que potencializem iniciativas, como o GERUS, que podem contribuir efetivamente para o enfrentamento dos problemas locais e propor soluções coletivas para a melhoria da qualidade de vida. Este último aspecto certamente merece o desenvolvimento de outros estudos mais aprofundados, que analisem e relacionem as dinâmicas político-institucionais e os processos de trabalho em saúde.

\section{Referências}

ADORNO, R. C. F; CASTRO, A. L. O exercício da sensibilidade: pesquisa qualitativa e a saúde como qualidade. Saúde e Sociedade, São Paulo, v.3, n.2, p.17285,1994.

ARRETCHE, M. T. S. Políticas sociais no Brasil: descentralização em um estado federativo. Revista Brasileira de Ciências Sociais, São Paulo, v.14, n.40, p.111-141, jun. 2001.
FERNANDEZ, J. C. A.; MENDES, R. Subprefeituras da cidade de São Paulo e políticas públicas para a qualidade de vida. São Paulo: CEPEDOC Cidades saudáveis, 2003.

FERREIRA, A. S. Competências gerenciais para unidades básicas do Sistema Único de Saúde. Ciência e Saúde Coletiva, Rio de Janeiro, v. 9, n.1, p.69-76, 2004.

FUNDAÇÃO INSTITUTO BRASILEIRO DE GEOGRAFIA E ESTATÍSTICA. Censo demográfico 2ooo: estimativa 2002. Rio de Janeiro: Secretaria Municipal de Planejamento- Deinfo, 2002.

FUNDAÇÃO INSTITUTO BRASILEIRO DE GEOGRAFIA E ESTATÍSTICA. Censo demográfico 20oo. Rio de Janeiro, 2000.

FUNDAÇÃO INSTITUTO BRASILEIRO DE GEOGRAFIA E ESTATÍSTICA. População residente em favelas, censo 20oo, contagem 1996. Rio de Janeiro, 2000.

HORTALE, V. A. O conceito de descentralização aplicado aos serviços de saúde: dimensões, padrões e regularidades. Revista de Administração Pública, Rio de Janeiro, v. 1, n.3.p. 23-35, maio/jun. 1997.

INOJOSA, R. M. Intersetorialidade e a configuração de um novo paradigma organizacional. Revista de Administração Pública, Rio de Janeiro, v.2, n.32, p.35-48, mar./abr.1998.

MENDES, E. V. Uma agenda para a saúde. São Paulo: Editora HUCITEC, 1996.

MINAYO, M. C. (Org.) et al. Pesquisa social: teoria, método e criatividade. Petrópolis: Vozes, 1994.

PATTON, M. Q. Qualitative evaluation methods. London: Sage Publications,1987.

SANTANA, J. P.(Org.). Desenvolvimento gerencial de Unidades Básicas do Sistema Único de Saúde (SUS). Brasília: Organização Pan- Americana de Saúde, 1997.

SÃo PAULO. Prefeitura do Município. Comunicado SMS/o01/2001. Diretrizes gerais para SMS. Diário Oficial do Município de São Paulo. São Paulo, 25 jan. 2001.

SÃO PAULO. Prefeitura do Município. Lei Nº 13.399/ 01/o8/2002. Diário Oficial do Município de São Paulo. São Paulo, 1 ago. 2002. 
SÃO PAULO. Prefeitura do Município. Secretaria do Governo Municipal, Assessoria de Planejamento (Sisem). Demografia- População, área, densidade e crescimento demográfico, município de São Paulo, evolução de 1991 a 200o. In: UBITRATAN, P.S.; BARRETA, D.(Org.). As subprefeituras do Município de São Paulo. São Paulo: Hucitec, 2004.

SÃO PAULO. Secretaria Municipal da Saúde. Assessoria de Planejamento (Sisem). Taxa de homicídios por 100.000 habitantes, Subprefeituras do município de São Paulo, 2002. In: UBITRATAN, P. S.; BARRETA, D. (Org.). As subprefeituras do Município de São Paulo. São Paulo: Hucitec, 2004.

SÃO PAULO. Secretaria Municipal da Saúde. Coordenadorias de Saúde das Subprefeituras de São Paulo. Revista Saúde São Paulo, São Paulo, v. 1, n. 2, p.16-17, jun. 2004.

SPINK, M. J. P.; MEDRADO, B. Produção de sentidos no cotidiano: uma abordagem teóricometodológica para análise das práticas discursivas. In: SPINK, M. J. P. (Org.). Práticas discursivas e produção de sentidos no cotidiano: aproximações teóricas e metodológicas. São Paulo: Cortez, 1999.

VECINA, G. N.; TERRA, V. A universidade e a formação de recursos humanos na gestão da saúde 1998. Revista Administração Pública, Rio de Janeiro, v. 32, n.2, p.185-194. mar./abr.1998.
WESTPHAL, M. F. MENDES, R, COMARU F. A. A promoção da saúde e as cidades. Brasília: Ministério da Saúde, 2004. Publicação no prelo.

WESTPHAL, M. F; BÓGUS, C. M; FARIA, M. M. Grupos focais: experiências precursoras em programa educativos em saúde no Brasil. Boletim da Oficina Sanitaria Panamericana, Washington, v. 120, n.6, p. $472-82,1986$.

\section{Anexo}

\section{Roteiro - grupo focal}

1. Como é ser gerente de UBS na região dos Distritos de Saúde Parelheiros, Marsilac, Grajaú e Socorro?

2. Como você vê o papel do gerente diante da criação das subprefeituras?

3. O GERUS contribuiu para o desenvolvimento do seu papel gerencial? Comente.

4. O que você considera importante para desenvolver o seu papel de gerente? Comente.

5. Em poucas palavras, depois de toda essa nossa discussão, o que é ser um gerente de UBS. 